\title{
Site-Specific Radiometal Labeling and Improved Biodistribution Using ABY-027, A Novel HER2-Targeting Affibody Molecule-Albumin-Binding Domain Fusion Protein
}

\author{
Anna Orlova ${ }^{1}$, Andreas Jonsson ${ }^{2}$, Daniel Rosik ${ }^{2}$, Hans Lundqvist ${ }^{3}$, Malin Lindborg ${ }^{4}$, Lars Abrahmsen ${ }^{4}$, Caroline Ekblad ${ }^{4}$, \\ Fredrik Y. Frejd ${ }^{3,4}$, and Vladimir Tolmachev ${ }^{3}$ \\ ${ }^{\text {I} P r e c l i n i c a l ~ P E T ~ P l a t f o r m, ~ M e d i c i n a l ~ C h e m i s t r y, ~ U p p s a l a ~ U n i v e r s i t y, ~ U p p s a l a, ~ S w e d e n ; ~}{ }^{2}$ Division of Molecular Biotechnology, \\ School of Biotechnology, Royal Institute of Technology, Stockholm, Sweden; ${ }^{3}$ Division of Biomedical Radiation Sciences, Rudbeck \\ Laboratory, Uppsala University, Uppsala, Sweden; and ${ }^{4}$ Affibody AB, Solna, Sweden
}

Because of their better penetration, smaller targeting proteins may be superior to antibodies for radioimmunotherapy of solid tumors. Therefore, Affibody molecules $(6.5 \mathrm{kDa})$ have a potential for being suitable as targeted moiety for radiolabeled therapeutic proteins. Previous studies have demonstrated that a fusion of an Affibody molecule with an albumin-binding domain (ABD) provides a strong noncovalent binding to albumin in vivo. This strong noncovalent binding can be used for reduction of the renal uptake of the Affibody molecule while maintaining a size smaller than that of an antibody, which is important when using residualizing radionuclide labels conjugated to Affibody molecules. The goal of this study was to design and evaluate a new targeting Affibody-ABD fusion protein with improved biodistribution properties for radionuclide therapy. Methods: $A$ novel Affibody-based construct, $Z_{\text {HER2:2891 }}-A_{B} D_{035}-D O T A$ (ABY-027), was created by fusion of the reengineered HER2binding Affibody molecule $Z_{\text {HER2:2891 }}$ to the $N$ terminus of the high-affinity $\mathrm{ABD}_{035}$, and a maleimido-derivative of DOTA was conjugated at the $C$ terminus of the construct. Binding and processing of ${ }^{177}$ Lu-ABY-027 by HER2-expressing cells were evaluated in vitro. Targeting of HER2-expressing SKOV-3 xenografts was evaluated in BALB/C nu/nu mice and compared with targeting of previously reported ABD-( $\left.Z_{\text {HER2:342 }}\right)_{2}$. Results: The binding affinity (dissociation constant) of ABY-027 to HER2 (74 pM) was the same as for the parental $Z_{\text {HER2:2891 }}(76$ pM). ABY-027 was stably labeled with ${ }^{177} \mathrm{Lu}$ and ${ }^{111}$ In with preserved specific binding to HER2-expressing cells in vitro. In vivo receptor saturation experiments demonstrated that targeting of SKOV-3 xenografts in BALB/C nu/nu mice was HER2-specific. ${ }^{177} \mathrm{Lu}-\mathrm{ABY}-027 \mathrm{dem}-$ onstrated substantially (2- to 3-fold) lower renal and hepatic uptake than previously assessed HER2-specific Affibody-based albumin-binding agents. Tumor uptake of radiolabeled ABY027 at $48 \mathrm{~h}$ after injection was 2-fold higher than that for previously reported $A B D-\left(Z_{\text {HER2:342 }}\right)_{2}$. Conclusion: An optimized molecular design of an ABD fusion protein resulted in an Affibody molecule construct with better properties for therapy. Fully preserved in vivo targeting of the fusion protein was shown

\footnotetext{
Received Jul. 1, 2012; revision accepted Nov. 27, 2012.

For correspondence or reprints contact: Anna Orlova, Dag Hammarskjöldsv 14C, $3 \mathrm{tr}, 75183$ Uppsala, Sweden.

E-mail: anna.orlova@pet.medchem.uu.se

Published online Mar. 25, 2013.

COPYRIGHT @ 2013 by the Society of Nuclear Medicine and Molecular Imaging, Inc.
}

in xenografted mice. Site-specific coupling of DOTA provides a uniform conjugate and creates the potential for labeling with a broad range of therapeutic radionuclides. The biodistribution of ${ }^{177} \mathrm{Lu}-\mathrm{ABY}-027$ in a murine model suggests it is more suitable for therapy than alternative approaches.

Key Words: HER2; affibody molecule; ${ }^{177} \mathrm{Lu}$; targeting therapy; albumin

J Nucl Med 2013; 54:961-968

DOI: 10.2967/jnumed.112.110700

\section{D} uring the last decades, impressive progress in the treatment of disseminated cancer has been achieved. Conventional chemotherapy has been supplemented with new therapeutic modalities that exploit the recognition of unique molecular features of cancer cells or the microenvironment in tumor tissue, resulting in increased selectivity of several therapies and reduced toxicity to healthy tissues. One cancerassociated molecular target for therapy is the human epidermal growth factor receptor type 2 (HER2, Neu, ErbB2). HER2 is a member of the epidermal growth factor tyrosine kinase receptor family involved in the regulation of cell proliferation, motility, and apoptosis suppression. HER2 is overexpressed in many types of carcinomas and is considered to be part of the malignant phenotype (1). A recent review reports a HER2 overexpression frequency of $25 \%$ for breast cancer, $20 \%-70 \%$ for hormone-refractory prostate cancers, and $35 \%-55 \%$ for colorectal cancer (1). In contrast, HER2 expression in healthy adult tissues is low or nondetectable. Treatment of HER2-expressing breast cancer with trastuzumab, a HER2-specific antibody, significantly prolongs survival of breast cancer patients (2). Unfortunately, many HER2-expressing breast cancers have primary resistance, and others develop treatment-induced resistance to the HER2-binding monoclonal antibody trastuzumab within 1 y (3). Resistance often develops despite sustained HER2 expression (3).

The persistence of HER2 expression may be used for targeting a payload to the tumor cells, including cytotoxic 
agents and radionuclides (4). Radionuclide therapy offers the advantage of a cross-fire effect occurring when nuclides delivered to cancer cells irradiate neighboring malignant cells, which can overcome issues associated with heterogeneous expression of a particular malignant target or nonuniform penetration of targeting agents into the tumor tissue (5). Radioimmunotherapy of non-Hodgkin lymphoma using the radiolabeled antibodies ${ }^{131} \mathrm{I}$-tositumomab and ${ }^{90}$ Y-ibritumomab tiuxetan has demonstrated high response rates and constitutes an encouraging example of targeted radionuclide therapy (6). However, targeted radionuclide therapy of solid tumors using immunoglobulins remains a challenge (7). The major reasons are the long residence time of the large $(150 \mathrm{kDa})$ immunoglobulins in circulation, resulting in irradiation of healthy tissues, such as bone marrow, and slow extravasation and penetration into the tumor, limiting the therapeutic effect (8). The slow diffusion and poor penetration of antibodies into solid tumors has raised interest in smaller targeting proteins as carriers for radionuclides and other payloads. Proteins with a mass below the cutoff for renal clearance $(\sim 60 \mathrm{kDa})$ are rapidly lost from the bloodstream (9). Despite the short circulatory half-life, high-affinity proteins may yield high levels of solid tumor targeting, probably because of greatly superior tumor penetration, as exemplified with a 6.5-kDa HER2-binding Affibody (Affibody AB) molecule $(10,11)$.

Our approach is to make targeted therapeutic agents based on Affibody molecules. Affibody molecules constitute a new class of affinity proteins based on a 58-aminoacid residue protein domain derived from staphylococcal protein A $(12,13)$. Affibody molecules combine small size $(\sim 6.5 \mathrm{kDa})$ with high affinity and specificity for the target. The most studied is the $\mathrm{Z}_{\mathrm{HER} 2: 342}$ Affibody molecule, binding to HER2 with high affinity (dissociation constant $\left[\mathrm{K}_{\mathrm{D}}\right]$, $22 \mathrm{pM}$ ) (11). The clinical utility for imaging of HER2 expression in patients with metastasized breast cancer was demonstrated using a chemically manufactured variant of $\mathrm{Z}_{\mathrm{HER} 2: 342}$ labeled with ${ }^{111} \mathrm{In}$ or ${ }^{68} \mathrm{Ga}$ (14). The main obstacle for using Affibody molecules with residualizing radiometal labels for radionuclide therapy is their predominant renal excretion associated with nearly quantitative tubular reabsorption (15-17). The renal concentration of radioactivity in a murine model at $4 \mathrm{~h}$ after injection was as high as 250 percentage injected dose per gram $(\% \mathrm{ID} / \mathrm{g})$ for Affibody variants labeled with ${ }^{111} \mathrm{In}$ or ${ }^{177} \mathrm{Lu}$ using a DOTA chelator $(15,16)$.

One of the approaches for the generation of the new targeting agents is to assemble the targeting molecule from smaller parts, providing the desired biologic and pharmacologic properties. In our previous studies $(17,18)$, we demonstrated that fusion of the anti-HER2 Affibody molecule dimer $\left(\mathrm{Z}_{\mathrm{HER} 2: 342}\right)_{2}$ to a $5-\mathrm{kDa}$, non-cysteine-containing, 3-helix-bundle albumin-binding domain (ABD) modified the pharmacokinetics. The residence time in blood was appreciably extended, and the renal uptake was reduced 20- to 30-fold in comparison with non-ABD-fused Affibody molecules. The ${ }^{177} \mathrm{Lu}-\mathrm{CHX}-\mathrm{A}^{\prime \prime}-\mathrm{DTPA}-\mathrm{ABD}-\left(\mathrm{Z}_{\mathrm{HER} 2: 342}\right)_{2}$ conjugate demonstrated a curative effect in murine microxenografts with high HER2 expression (17). In a parallel study, Dennis et al. showed that a fusion protein of a Fab fragment and an albumin-binding peptide was superior to the Fab fragment in terms of tumor penetration (19). Serum albumin has previously been shown to preferentially locate in tumors, compared with normal tissue (20), and the favorable tumor penetration of an albumin-associated fusion protein might be a result of combining favorable localization with highaffinity binding to a protein on the tumor cell surface.

In the present study, the improved HER2-targeted Affibody molecule $\mathrm{Z}_{\mathrm{HER} 2: 2891}$ has been combined with an engineered $\mathrm{ABD}$ fusion protein $\mathrm{ABD}_{035}$, which has a high affinity $\left(\mathrm{K}_{\mathrm{D}}, 50-500 \mathrm{fM}\right)$ for human serum albumin (21). $\mathrm{ABD}_{035}$ also displays higher affinity for murine serum albumin than the parent ABD, found in the HER2-binding fusion protein used in our previous study. The Affibody molecule $Z_{\mathrm{HER} 2: 2891}$ is an engineered derivative of $Z_{\text {HER2:342 }}$ used in that study. The target-binding surface has been retained, but the nonbinding surface has been optimized and is distinctly different from the parental molecule (22). $Z_{\text {HER2:2891 }}$ was recently validated in a clinical trial and was shown to target HER2-expressing metastatic lesions in breast cancer patients (23). In the fusion protein, denoted ABY-027, the Affibody moiety was inserted $\mathrm{N}$-terminally of the ABD, to separate the HER2 and the albumin-binding surfaces as far as possible. In the Affibody molecule, the HER2-binding surface is located on helices 1 and 2, whereas in the ABD the albumin-binding surface is located on helices 2 and 3 of the triple helical protein domain. Last, the chelating group used for labeling the fusion protein was site-specifically introduced, using a unique cysteine residue specifically introduced for this purpose.

The goal of this study was to evaluate the biodistribution and targeting properties of the new potential anti-HER2 therapeutic agent $\mathrm{Z}_{\mathrm{HER} 2: 2891}-\mathrm{ABD}_{035}$-C-DOTA (further denoted ABY-027).

\section{MATERIALS AND METHODS}

\section{General}

${ }^{177} \mathrm{Lu}$-lutetium and ${ }^{111} \mathrm{In}$-chloride were from Covidien. Buffers used for conjugation and labeling were purified from metal contaminations using a Chelex 100 resin (Bio-Rad Laboratories). The NAP-5 size-exclusion columns were from GE Healthcare. The radioactivity was measured using an automated $\gamma$-counter with a 7.62-cm (3-in) $\mathrm{NaI}(\mathrm{Tl})$ detector (1480 WIZARD; Wallac Oy). The radioactivity distribution on the instant thin-layer chromatography strips was measured by a Cyclone Storage Phosphor System and analyzed using the OptiQuant image analysis software (PerkinElmer). CHX-A" -DTPA-ABD- $\left(\mathrm{Z}_{\mathrm{HER} 2: 342}\right)_{2}$ was produced and labeled with ${ }^{111} \mathrm{In}$ as described earlier $(17,18)$.

\section{Production of $\mathbf{Z}_{\text {HER2:2891- }}$ ABD $_{035}$-DOTA (ABY-027)}

A DNA fragment encoding $Z_{\text {HER2:2891 }}$ (22) was subcloned into a pET (Novagen)-derived expression vector containing a gene encoding $\mathrm{ABD}_{035}$ (21) with a C-terminal cysteine, resulting in the expression vector pAY02107. Soluble protein was produced in Escherichia coli and purified using human serum albumin 
(HSA)-Sepharose (CNBr-activated Sepharose 4FF; Amersham Biosciences $A B$ ) as described earlier (17). The $Z_{\mathrm{HER} 2: 2891}-\mathrm{ABD}_{035}$ was conjugated to maleimide-DOTA (Macrocyclics) as described by Ahlgren et al. (24). The conjugate was analyzed by high-performance liquid chromatography and online mass spectrometry (HPLC-MS) using an Agilent 1100 HPLC/MSD equipped with Zorbax 300SB-C18 $(4.6 \times 150,3.5 \mu \mathrm{m})$ column. The binding kinetics and affinity of ABY-027 for HER2-Fc chimera and for HSA were measured using a Biacore 2000 instrument (GE Healthcare) according to methods described earlier $(21,22)$.

\section{Labeling Chemistry}

For labeling, an aliquot of $50 \mu \mathrm{g}$ of ABY-027 in $0.5 \mathrm{M}$ sodium acetate containing ascorbic acid $(10 \mathrm{mg} / \mathrm{mL}), \mathrm{pH} 5.5$, was mixed with a predetermined amount $(65-76 \mathrm{MBq})$ of ${ }^{177} \mathrm{Lu}$ or ${ }^{111} \mathrm{In}$ and incubated at $60^{\circ} \mathrm{C}$ or $80^{\circ} \mathrm{C}$ for $30 \mathrm{~min}$. A metal-to-ligand ratio of 1:5 was used for labeling. For routine quality control of the labeling, silica gel-impregnated glass fiber sheets for instant thin-layer chromatography (Gelman Sciences Inc.), eluted with $0.2 \mathrm{M}$ citric acid, were used.

For a stability test, 2 aliquots of ${ }^{177} \mathrm{Lu}-\mathrm{ABY}-027$ were mixed with a 500-fold molar excess of ethylenediaminetetraacetic acid, incubated for $60 \mathrm{~min}$ at ambient temperature and analyzed as described above. An amount of non-protein-bound ${ }^{177} \mathrm{Lu}$ was compared with a standard not exposed to ethylenediaminetetraacetic acid.

\section{In Vitro Studies}

The HER2-expressing ovarian carcinoma cell line SKOV-3 (American Type Culture Collection, LGC Standards AB), displaying approximately $1.6 \times 10^{6}$ HER2 receptors per cell (25), was used in this study. All experiments were performed in triplicate.

The binding specificity for HER2-expressing cells of the ${ }^{177} \mathrm{Lu}-$ ABY-027 conjugates labeled at $60^{\circ} \mathrm{C}$ or $80^{\circ} \mathrm{C}$ was tested using methods described earlier (17). For HER2 blocking, a 1,000-fold excess of nonlabeled Affibody molecule was used. Cells were incubated with labeled conjugate $(0.5 \mathrm{nM})$ for $1 \mathrm{~h}$ at $37^{\circ} \mathrm{C}$, and the percentage of cell-bound radioactivity was determined in blocked and nonblocked samples.

The antigen-binding capacity of ${ }^{177} \mathrm{Lu}-\mathrm{ABY}-027$ labeled at $60^{\circ} \mathrm{C}$ or $80^{\circ} \mathrm{C}$ was determined using methods described earlier (17). A solution of ${ }^{177} \mathrm{Lu}-\mathrm{ABY}-027$ in cell culture medium $(1 \mathrm{~mL}$, $0.06 \mathrm{pmol}$ ) was added to cell pellets to provide an approximately 100 -fold molar excess of receptor over conjugate. The cells were incubated for $5 \mathrm{~h}$ at $4{ }^{\circ} \mathrm{C}$, and the percentage of cell-bound radioactivity was determined.

The cellular retention and processing of ${ }^{177} \mathrm{Lu}-\mathrm{ABY}-027$ by HER2-expressing cells were studied according to the method described earlier (26). Cells were incubated with radiolabeled Affibody conjugate $(5 \mathrm{nM})$ for $1 \mathrm{~h}$ at $4^{\circ} \mathrm{C}$. The medium was then exchanged, and incubation was continued at $37^{\circ} \mathrm{C}$. The membrane-associated radioactivity was determined at preselected time points. The percentage of small $(<5 \mathrm{kDa})$ radiocatabolites in the incubation medium was determined by analysis using NAP-5 sizeexclusion columns.

\section{In Vivo Studies}

The animal studies were approved by the Local Ethics Committee for Animal Research. The tumor was grafted by subcutaneous injection of approximately $10^{7}$ SKOV-3 cells in the hind legs of female BALB/c nu/nu mice. Tumors were allowed to grow for $4-5$ wk before experiments. In all biodistribution studies, groups of 4-6 animals were used. At predetermined time points, the animals were euthanized by heart puncture under anesthesia (ketamine [Ketalar, $10 \mathrm{mg} / \mathrm{mL}$; Pfizer] and xylazin [Rompun, 1 $\mathrm{mg} / \mathrm{mL}$; Bayer], $20 \mu \mathrm{L}$ of solution per gram of body weight). Blood and organ samples were excised and weighed, and their radioactivity was measured. The tissue uptake values were calculated as $\% \mathrm{ID} / \mathrm{g}$.

For comparison, 2 groups of mice were injected with $50 \mathrm{kBq}$ of ${ }^{111} \mathrm{In}-\mathrm{ABY}-027(10 \mu \mathrm{g})$ and ${ }^{111} \mathrm{In}-\mathrm{CHX}-\mathrm{A}^{\prime \prime}$-DTPA-ABD$\left(\mathrm{Z}_{\mathrm{HER} 2: 342}\right)_{2}(16 \mu \mathrm{g})$ in $100 \mu \mathrm{L}$ of phosphate-buffered saline (PBS), and biodistribution was measured at $48 \mathrm{~h}$ after injection. The average tumor weight was $0.2 \pm 0.1 \mathrm{~g}$.

To evaluate the influence of the injected ABY-027 protein dose on tumor uptake and biodistribution of ${ }^{177} \mathrm{Lu}-\mathrm{ABY}-027,3$ groups of mice were injected with $20 \mathrm{kBq}$ in $100 \mu \mathrm{L}$ of PBS per mouse. The protein dose was adjusted to 1,10 , or $50 \mu \mathrm{g}$ per mouse by mixing with nonlabeled ABY-027. The biodistribution was compared at $48 \mathrm{~h}$ after injection. The average tumor weight was $0.14 \pm 0.07 \mathrm{~g}$.

To evaluate the biodistribution and tumor-targeting capacity of the labeled compound, and to obtain input data for dosimetry calculations, 24 mice were injected with $120 \mathrm{kBq}$ of ${ }^{177} \mathrm{Lu}-\mathrm{ABY}-$ 027 (protein dose, $10 \mu \mathrm{g}$ in $100 \mu \mathrm{L}$ of PBS) each. The average tumor weight was $0.10 \pm 0.05 \mathrm{~g}$. At predetermined time points (4, $24,48,72,168$, and $336 \mathrm{~h}$ after injection), a group of 4 mice was euthanized, and the concentration of the radioactivity in tumors and tissues was determined. To confirm HER2-specific tumor targeting of ${ }^{177} \mathrm{Lu}-\mathrm{ABY}-027,4$ mice were injected with $1 \mathrm{mg}$ each of nonlabeled ABY-027. One hour later, each mouse was injected with $120 \mathrm{kBq}$ of ${ }^{177} \mathrm{Lu}-\mathrm{ABY}-027$ (protein dose, $10 \mu \mathrm{g}$ in $100 \mu \mathrm{L}$ of PBS). The animals were euthanized at $48 \mathrm{~h}$ after injection, and the biodistribution of radioactivity was determined.

\section{Dosimetry Calculations}

The dosimetry calculations were performed according to methods described earlier (17). Briefly, the organ uptake values from the biodistribution study, noncorrected for physical half-life, were time-integrated by the trapezoid method to obtain the residence time per gram of tissue. The extrapolated area was less than a few percent in all organs. In the absorbed dose calculations, S values for ${ }^{177} \mathrm{Lu}$ were obtained from RADAR (RAdiation Dose Assessment Resource) phantoms (unit density spheres) (http://www.doseinforadar.com/). The $S$ value for a $1-\mathrm{g}$ sphere $(0.0233 \mathrm{mGy} / \mathrm{MBq} \cdot \mathrm{s})$ was used generally to calculate all organ doses. This simplified dosimetry calculation is motivated by the fact that the low-energy $\beta$-particles in the ${ }^{177} \mathrm{Lu}$ decay are locally absorbed, and photons and other penetrating radiations are contributing to a low extent, meaning that the crosstalk between different organs in the mouse is negligible.

\section{Statistics}

Statistical analyses were performed by unpaired, 2-tailed $t$ tests using Prism (version 4.00; GraphPad Software) for Windows (Microsoft). A $P$ value below 0.05 was considered significant.

\section{RESULTS}

Characterization of $\mathbf{Z}_{\text {HER2:2891 }}-\mathrm{ABD}_{\text {035-DOTA (ABY-027) }}$

The identity and purity of $\mathrm{Z}_{\mathrm{HER} 2: 2891}-\mathrm{ABD}_{035}$-cys and $\mathrm{Z}_{\mathrm{HER} 2: 2891}-\mathrm{ABD}_{035}$-DOTA were characterized by HPLC-MS and sodium dodecyl sulfate polyacrylamide gel electrophoresis. Both analyses confirmed the expected mass of the 
constructs (12,122 and 12,646 Da, respectively). The purity of $\mathrm{Z}_{\mathrm{HER} 2: 2891}-\mathrm{ABD}_{035}$-DOTA was above $98 \%$, as determined by HPLC-MS. No variants other than the 1:1 chelator-to-protein ratio were detected. The binding kinetics of ABY-027 to the extracellular domain of HER2 were measured using surface plasmon resonance. The association rate constant $\left(\mathrm{k}_{\mathrm{a}}\right)$ was $(8.78 \pm 0.06) \times 10^{6} \mathrm{M}^{-1} \mathrm{~s}^{-1}$, the dissociation rate constant $\left(\mathrm{k}_{\mathrm{d}}\right)$ was $(6.45 \pm 0.03) \times 10^{-4} \mathrm{~s}^{-1}$, and the dissociation constant $\left(\mathrm{K}_{\mathrm{D}}=\mathrm{k}_{\mathrm{d}} / \mathrm{k}_{\mathrm{a}}\right)$ was $74 \mathrm{pM}$. A retained high-albumin-binding affinity was confirmed and shown to be similar to that of the single-domain $\mathrm{ABD}_{035}$ used as control. Because of high affinity, it was not possible to determine the $\mathrm{k}_{\mathrm{d}}$ using surface plasmon resonance

\section{Labeling Chemistry}

The labeling of ABY-027 was rapid and efficient under the selected conditions. Labeling with ${ }^{177} \mathrm{Lu}$ at $60^{\circ} \mathrm{C}$ provided yields of $94 \% \pm 7 \%$ after $15 \mathrm{~min}$ and $98 \% \pm 2 \%$ after $30 \mathrm{~min}(n=6)$. At $80^{\circ} \mathrm{C}$, the yields were $96 \% \pm 3 \%$ and $97 \% \pm 1 \%$ after 15 and $30 \mathrm{~min}$, respectively. The specific radioactivity was $1.3-1.5 \mathrm{MBq} / \mu \mathrm{g}(16.4-19.3 \mathrm{GBq} / \mu \mathrm{mol})$, depending on the specific radioactivity of ${ }^{177} \mathrm{Lu}$-lutetium chloride. Challenge with a 500-fold molar excess of ethylenediaminetetraacetic acid during $1 \mathrm{~h}$ did not reveal any measurable release of radioactivity. Labeling yields were $98.8 \%$ for ${ }^{111} \mathrm{In}-\mathrm{ABY}-027$ and $99.1 \%$ for ${ }^{111} \mathrm{In}-\mathrm{CHX}-$ $\mathrm{A}^{\prime \prime}$-DTPA-ABD- $\left(\mathrm{Z}_{\mathrm{HER} 2: 342}\right)_{2}$.

\section{Cellular Binding and Retention}

The binding of ${ }^{177} \mathrm{Lu}-\mathrm{ABY}-027$, labeled at $60^{\circ} \mathrm{C}$ or $80^{\circ} \mathrm{C}$, was significantly decreased by preincubation with an excess of nonlabeled compound that demonstrated receptor-mediated binding (Fig. 1).The binding-competent fraction of ${ }^{177} \mathrm{Lu}-$ ABY-027 labeled at $60^{\circ} \mathrm{C}$ during $30 \mathrm{~min}$ was $88 \% \pm 1 \%$. Increasing the labeling temperature up to $80^{\circ} \mathrm{C}$ significantly decreased the binding-competent fraction to $81 \% \pm 2 \%$ $(P=0.02)$. Because labeling at $80^{\circ} \mathrm{C}$ did not provide higher yield or more rapid labeling, further biologic experiments were performed with conjugates labeled at $60^{\circ} \mathrm{C}$.

Cellular retention and processing experiments demonstrated good retention of ${ }^{177} \mathrm{Lu}$ radioactivity after interrupted incubation of SKOV-3 cells with ${ }^{177} \mathrm{Lu}-\mathrm{ABY}-027$ (Fig.

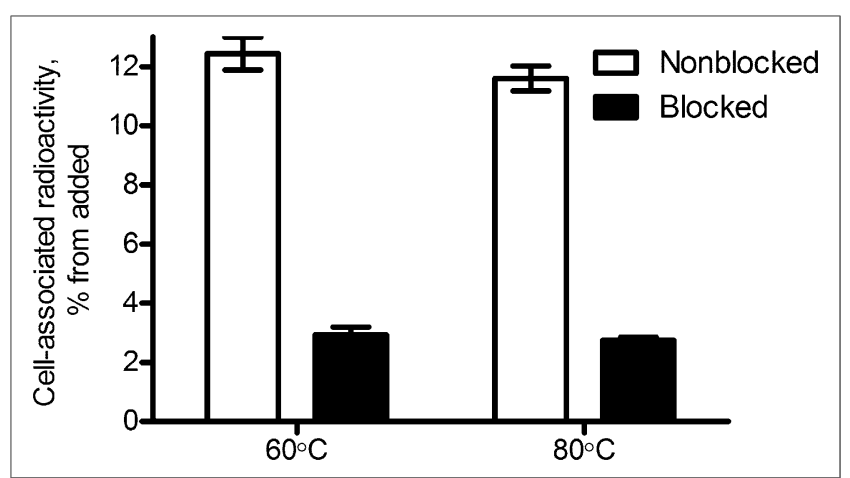

FIGURE 1. In vitro specificity test for ${ }^{177} \mathrm{Lu}-\mathrm{ABY}-027$ labeled at $60^{\circ} \mathrm{C}$ and $80^{\circ} \mathrm{C}$ on SKOV-3 cells (average of $3 \pm \mathrm{SD}$ ).
2A): half of the cell-associated radioactivity was retained at $24 \mathrm{~h}$ after interrupted incubation. Most of the radioactivity release occurred during the first $4 \mathrm{~h}$. Only half of the cellassociated radioactivity had been internalized after $24 \mathrm{~h}$. Size-exclusion chromatography of incubation medium showed that after $24 \mathrm{~h}$ of incubation approximately $40 \%$ of the radioactivity in the medium was associated with lowmolecular-weight $(<5 \mathrm{kDa})$ radiocatabolites, indicating that some of the conjugate was processed intracellularly and radiocatabolites were excreted (Fig. 2B).

\section{Tumor Uptake and Biodistribution}

The direct comparison of the biodistribution pattern of ${ }^{111}$ In-ABY-027 and ${ }^{111}$ In-CHX-A" - DTPA-ABD- $\left(\mathrm{Z}_{\text {HER2:342 }}\right)_{2}$ in tumor-bearing mice (Table 1) demonstrated a 2-fold-higher tumor uptake and 3-fold-lower radioactivity retention in kidneys for ${ }^{111} \mathrm{In}-\mathrm{ABY}-027$. The radioactivity concentration in other studied tissues was slightly higher for ${ }^{111}$ In-ABY-027. Data for ${ }^{111}$ In-CHX-A" -DTPA-ABD- $\left(Z_{\text {HER 2:342 }}\right)_{2}$ were in good agreement with published results $(17,18)$.
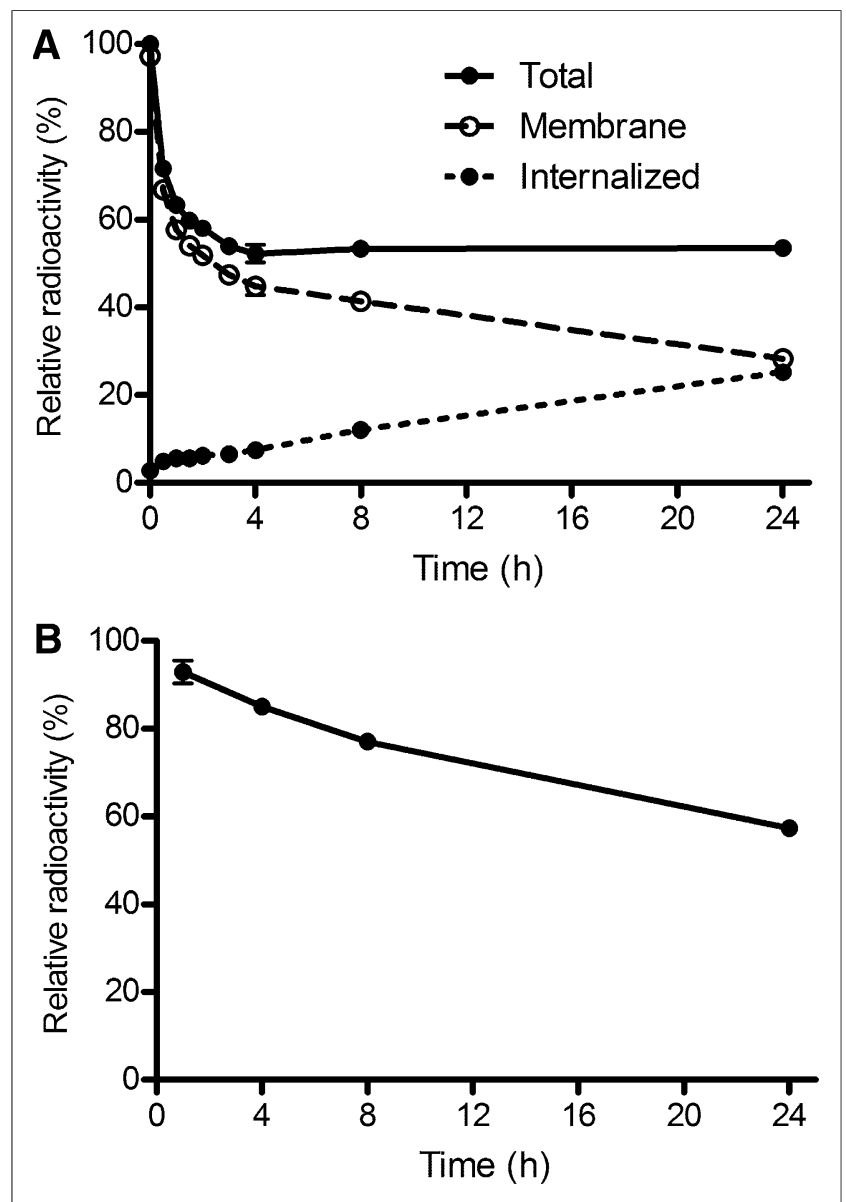

FIGURE 2. (A) Cellular processing of ${ }^{177} \mathrm{Lu}-\mathrm{ABY}-027$ in SKOV-3 cells after interrupted incubation (average of 3 samples $\pm S D$ ). In each sample, radioactivity was normalized by cell-associated radioactivity at time of interruption. (B) Size-exclusion analysis of incubation medium after interrupted incubation of ${ }^{177} \mathrm{Lu}-\mathrm{ABY}-027$ with SKOV-3 cells (average of $2 \pm S D$ ). 
TABLE 1

Comparison of Biodistribution of Radiolabeled Potential Affibody-Based Therapeutics in Tumor-Bearing Mice

\begin{tabular}{|c|c|c|c|c|c|c|}
\hline \multirow[b]{2}{*}{ Organ } & \multicolumn{6}{|c|}{ Concentration of radioactivity, $\% \mathrm{ID} / \mathrm{g}$ at $48 \mathrm{~h}$ after injection } \\
\hline & ${ }^{111} \ln -\mathrm{ABY}-027^{*}$ & $\begin{array}{c}{ }^{111} \text { In-CHX-A" } \\
\text { ABD- }\left(\mathrm{Z}_{\text {HER2:342 }}\right)_{2}{ }^{a}\end{array}$ & $\begin{array}{c}\text { 177 Lu- } \\
\text { ABY-027* }\end{array}$ & $\begin{array}{c}{ }^{177} \mathrm{Lu}-\mathrm{CHX}-\mathrm{A}^{\prime \prime}-\mathrm{DTPA}-\mathrm{ABD}- \\
\left(\mathrm{Z}_{\mathrm{HER} 2: 342}\right)_{2}{ }^{*}(17)\end{array}$ & $\begin{array}{l}{ }^{111} \mathrm{In} \text {-DOTA-ABD- } \\
\left(\mathrm{Z}_{\text {HER2:342 }}\right)^{\dagger}(18)\end{array}$ & $\begin{array}{l}{ }^{111} \text { In-DOTA-HSA- } \\
\left(\mathrm{Z}_{\text {HER2:342 }}\right)^{*}(33)\end{array}$ \\
\hline Tumor & $43 \pm 3$ & $22 \pm 7$ & $17 \pm 7$ & $26 \pm 4$ & $12 \pm 3$ & $17 \pm 1$ \\
\hline Blood & $5.9 \pm 0.8$ & $4.7 \pm 1.0$ & $5.3 \pm 0.4$ & $5.5 \pm 0.8$ & $4.6 \pm 1.0$ & $3.0 \pm 0.9$ \\
\hline Lung & $4.5 \pm 0.4$ & $3.4 \pm 0.7$ & $3.5 \pm 0.5$ & $3.5 \pm 0.5$ & $3.3 \pm 0.6$ & $2.6 \pm 0.6$ \\
\hline Liver & $7.0 \pm 0.9$ & $6 \pm 2$ & $3.0 \pm 0.7$ & $5.7 \pm 0.6$ & $5.2 \pm 0.8$ & $14 \pm 3$ \\
\hline Spleen & $5.4 \pm 0.8$ & $3.2 \pm 0.9$ & $2.9 \pm 0.5$ & $3.8 \pm 0.4$ & $5 \pm 2$ & $9 \pm 1$ \\
\hline Kidney & $6.0 \pm 0.6$ & $17 \pm 3$ & $3.9 \pm 0.6$ & $15.9 \pm 0.8$ & $18 \pm 2$ & $5.7 \pm 0.9$ \\
\hline Muscle & $1.0 \pm 0.2$ & $0.7 \pm 0.2$ & $1.4 \pm 0.4$ & $1.0 \pm 0.3$ & $0.7 \pm 0.2$ & $1.0 \pm 0.3$ \\
\hline Bone & $1.54 \pm 0.08$ & $1.0 \pm 0.3$ & $1.2 \pm 0.4$ & $1.8 \pm 0.6$ & $1.7 \pm 0.6$ & $3.33 \pm 0.05$ \\
\hline 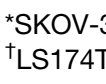 & varian carcino & la xenografts, high $\mathrm{HE}$ & 2 express & & & \\
\hline
\end{tabular}

Data on the influence of ABY-027 protein dose on tumor uptake and biodistribution of ${ }^{177} \mathrm{Lu}-\mathrm{ABY}-027$ in mice bearing SKOV-3 xenografts are presented in Figure 3. No dosedependent significant difference in organ accumulation of radioactivity at $48 \mathrm{~h}$ after injection of 1,10 , or $50 \mu \mathrm{g}$ of ABY-027 can be seen, except from a slightly (but significantly) higher retention of radioactivity in the carcass in mice injected with $1 \mu \mathrm{g}$ of conjugate. The apparent lower tumor concentration of ${ }^{177} \mathrm{Lu}$ in mice injected with $50 \mu \mathrm{g}$ of conjugate was not significantly separate from the value obtained with $10 \mu \mathrm{g}(P>0.05)$. In further experiments, a dose of $10 \mu \mathrm{g}$ per animal was used.

Data on the biodistribution of ${ }^{177} \mathrm{Lu}-\mathrm{ABY}-027$ in BALB/C $n u / n u$ mice bearing SKOV-3 xenografts at different time points after injection are presented in Figure 4 and Table 2. The mean tumor weight was $98 \pm 42 \mathrm{mg}$ in these experiments. Figure 4 presents the results of the targeting specificity test. The tumor radioactivity concentration at $48 \mathrm{~h}$ after injection was decreased from $17 \pm 7$ to $5 \pm 1 \% \mathrm{ID} / \mathrm{g}$ $(P<0.015)$ by preinjection of $1 \mathrm{mg}$ of nonlabeled ABY027. There was no significant difference in the radioactivity concentrations in all other organs and tissue samples. The decrease of ${ }^{177} \mathrm{Lu}-\mathrm{ABY}-027$ uptake in the tumor by presaturation of HER2 confirms that the tumor-targeting is receptor-mediated.

${ }^{177} \mathrm{Lu}-\mathrm{ABY}-027$ demonstrated efficient targeting of HER2expressing SKOV-3 xenografts in nude mice (Table 2). Already at $24 \mathrm{~h}$ after injection, the tumor radioactivity concentration was equal to the radioactivity concentration in blood and higher than in all other studied organs and tissue samples. The concentration of ${ }^{177} \mathrm{Lu}$ in tumors peaked at 48 $\mathrm{h}$ after injection, followed by slow washout. Up to $14 \mathrm{~d}$ after injection, the concentration of the radioactivity in the tumor exceeded the concentrations in any other organs. The blood clearance was slow, with an elimination half-life of $41 \mathrm{~h}$. The concentration of radioactivity in excretory organs (kidneys and liver) was lower than that in tumors and blood, peaking between 24 and $48 \mathrm{~h}$ after injection.

\section{Dosimetry Calculations}

The fraction of decays per gram of the administered activity (the residence time) was calculated by integrating the kinetic data (area under the curve) obtained in BALB/c $n u / n u$ mice bearing SKOV-3 tumor xenografts and is presented in Table 3. The contribution of extrapolated data was small, less than $10 \%$. The residence time was multiplied with a conversion factor to obtain the absorbed dose given in Table 3 . The data on a previous ABD-fused Affibody molecule variant, ${ }^{177} \mathrm{Lu}-\mathrm{CHX}-\mathrm{A}$ " -DTPA-ABD- $\left(\mathrm{Z}_{\mathrm{HER} 2: 342}\right)_{2}$ (17), are provided for comparison. The data were obtained in the same xenograft model and calculated using the same method. The comparison suggests that the ratio of doses to tumor and bone is equal for both conjugates. At the same time, tumor-to-liver (4.9 for ${ }^{177} \mathrm{Lu}-\mathrm{ABY}-027$ vs. 2.8 for ${ }^{177} \mathrm{Lu}-\mathrm{CHX}-\mathrm{A}^{\prime \prime}$-DTPAABD- $\left.\left(\mathrm{Z}_{\mathrm{HER} 2: 342}\right)_{2}\right)$ and tumor-to-kidney (3.9 for ${ }^{177} \mathrm{Lu}-\mathrm{ABY}-$ 027 vs. 1.4 for ${ }^{177} \mathrm{Lu}-\mathrm{CHX}-\mathrm{A}^{\prime \prime}$-DTPA-ABD- $\left.\left(\mathrm{Z}_{\mathrm{HER} 2: 342}\right)_{2}\right)$ dose ratios were appreciably higher for ${ }^{177} \mathrm{Lu}-\mathrm{ABY}-027$.

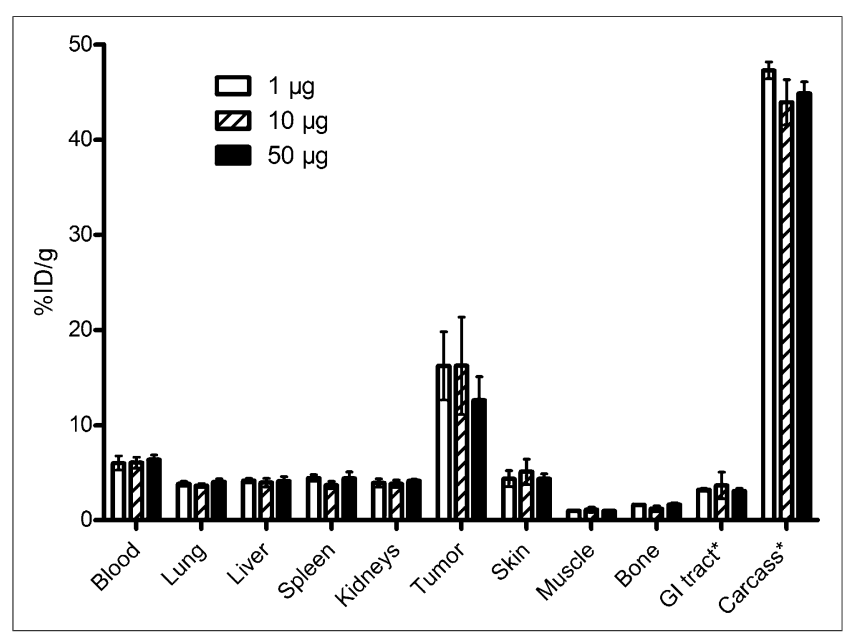

FIGURE 3. Uptake of radioactivity at $48 \mathrm{~h}$ after injection of 1,10 , or $50 \mu \mathrm{g}$ of ${ }^{177} \mathrm{Lu}-\mathrm{ABY}-027$ in SKOV-3-xenografted mice (average of $4-6, \% \mathrm{ID} / \mathrm{g} \pm \mathrm{SD}$ ). *For gastrointestinal (GI) tract (with content) and carcass, data are presented as \%ID per whole sample. 


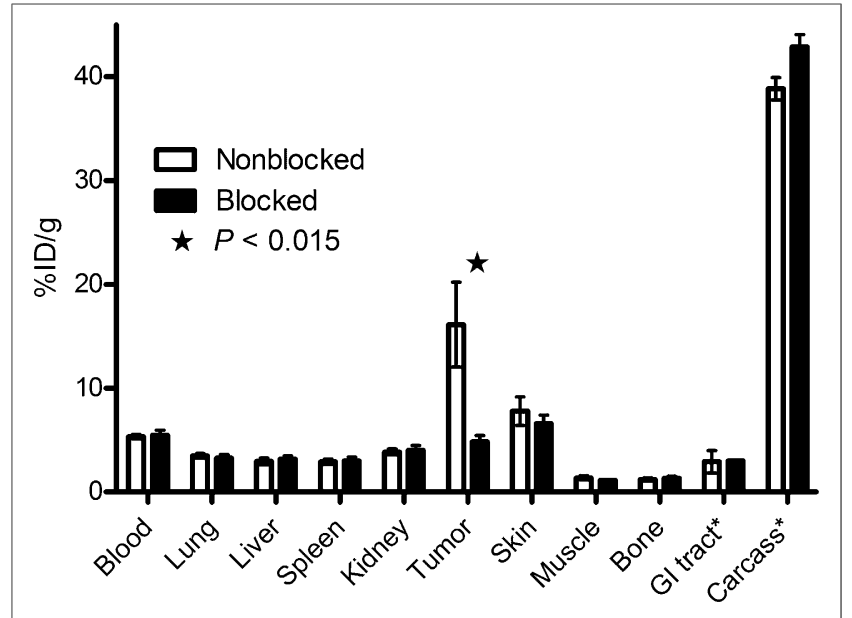

FIGURE 4. In vivo binding specificity of ${ }^{177} \mathrm{Lu}-\mathrm{ABY}-027,48 \mathrm{~h}$ after injection (average of $4, \% \mathrm{ID} / \mathrm{g} \pm \mathrm{SD}$ ). Blocked group was preinjected with $1 \mathrm{mg}$ of nonlabeled ABY-027. *For gastrointestinal (GI) tract (with content) and carcass, data are presented as \%ID per whole sample.

\section{DISCUSSION}

Targeted delivery of cytotoxic radionuclides is one potential option for treatment of HER2-expressing malignant tumors that are resistant to receptor-blocking therapies. Numerous attempts have been made, with smaller proteins having better extravasation and penetration in tumors than antibodies. However, several studies have demonstrated that the use of small HER2-targeting proteins such as $\mathrm{Fab}_{2}{ }_{2}(27)$, diabodies (28), DARPins (29), nanobodies $(30)$, and Affibody molecules $(16,24)$ labeled with radiometals all resulted in a high concentration of radioactivity in the kidneys. In each case, the renal concentration of radioactivity exceeded the tumor concentration severalfold, suggesting a high risk of severe nephrotoxicity as a side effect of targeted radionuclide therapy.

We have previously shown that fusion of a dimeric antiHER2 Affibody molecule with an ABD provided a protein capable of strong binding to albumin in vivo $(17,18)$. This binding prevented rapid glomerular filtration and tubular reabsorption and endowed a conjugate with favorable targeting properties for radiotherapy. Dosimetry calculations demonstrated that the dose to the tumor exceeded the dose to the kidney 1.4-fold, and curative treatment in a microxenograft model was possible (17). However, a further reduction of renal uptake would be desirable, and the present study was based on the hypothesis that a stronger binding to albumin might reduce the renal uptake of the radiolabeled conjugate. Furthermore, a strong binding to albumin is also expected to minimize losses due to lysosomal catabolism after pinocytosis of albumin carrying the conjugate, by enabling maximal use of neonatal Fc receptor-mediated salvage of albumin (31). Thus, $\mathrm{ABD}_{035}$ with femtomolar affinity for albumin may offer a pharmacokinetic advantage as a fusion partner to new targeting agents.

The surface plasmon resonance experiment showed that ABY-027 binds to HER2 with an affinity $\left(K_{D}, 74 \mathrm{pM}\right)$ identical to the affinity of parental $\mathrm{Z}_{\mathrm{HER} 2: 2891}\left(\mathrm{~K}_{\mathrm{D}}, 76 \mathrm{pM}\right)$. This finding supported our assumption that the HER2targeting moiety should preferably be situated at the $\mathrm{N}$ terminus of the fusion protein to preserve the affinity by minimizing sterical interference from ABD. The construct was efficiently and stably labeled with ${ }^{177} \mathrm{Lu}$ at $60^{\circ} \mathrm{C}$ with preserved HER2-binding capacity (Fig. 1). The cellular processing experiment suggested a moderate internalization rate (Fig. 2), although more rapid than that for the parent anti-HER2 Affibody molecule (24).

TABLE 2

Biodistribution of ${ }^{177}$ Lu-ABY-027 (Injected Dose, $10 \mu \mathrm{g}$ ) in BALB/C nu/nu Mice Bearing HER2-Expressing SKOV-3 Xenografts

\begin{tabular}{|c|c|c|c|c|c|c|}
\hline \multirow[b]{2}{*}{ Organ } & \multicolumn{6}{|c|}{ Concentration of radioactivity (\%ID/g) } \\
\hline & $4 \mathrm{~h}$ & $1 d$ & $2 d$ & $3 d$ & $7 d$ & $14 \mathrm{~d}$ \\
\hline Tumor & $1.1 \pm 0.5$ & $8 \pm 1$ & $17 \pm 7$ & $15 \pm 3$ & $7 \pm 2$ & $1.3 \pm 0.2$ \\
\hline Blood & $5 \pm 1$ & $8 \pm 2$ & $5.3 \pm 0.4$ & $3.4 \pm 0.4$ & $0.39 \pm 0.05$ & $0.020 \pm 0.003$ \\
\hline Heart & $1.3 \pm 0.3$ & $2.7 \pm 0.5$ & $2.4 \pm 0.3$ & $1.9 \pm 0.2$ & $0.7 \pm 0.2$ & $0.21 \pm 0.04$ \\
\hline Lung & $2.1 \pm 0.4$ & $4.1 \pm 0.7$ & $3.5 \pm 0.5$ & $2.4 \pm 0.2$ & $0.6 \pm 0.1$ & $0.13 \pm 0.03$ \\
\hline Liver & $1.0 \pm 0.2$ & $2.8 \pm 0.8$ & $3.0 \pm 0.7$ & $2.5 \pm 0.3$ & $1.2 \pm 0.2$ & $0.52 \pm 0.03$ \\
\hline Spleen & $0.6 \pm 0.1$ & $2.3 \pm 0.5$ & $2.9 \pm 0.5$ & $2.5 \pm 0.6$ & $1.9 \pm 0.6$ & $1.0 \pm 0.6$ \\
\hline Pancreas & $0.45 \pm 0.06$ & $1.3 \pm 0.2$ & $1.0 \pm 0.2$ & $0.8 \pm 0.2$ & $0.27 \pm 0.05$ & $0.10 \pm 0.03$ \\
\hline Stomach & $0.41 \pm 0.05$ & $1.5 \pm 0.2$ & $1.5 \pm 0.6$ & $0.9 \pm 0.1$ & $0.25 \pm 0.04$ & $0.08 \pm 0.01$ \\
\hline Kidney & $2.6 \pm 0.4$ & $4.3 \pm 0.8$ & $3.9 \pm 0.6$ & $2.98 \pm 0.09$ & $1.3 \pm 0.2$ & $0.39 \pm 0.06$ \\
\hline Muscle & $1.4 \pm 0.4$ & $1.3 \pm 0.2$ & $1.4 \pm 0.4$ & $0.9 \pm 0.2$ & $0.36 \pm 0.08$ & $0.09 \pm 0.03$ \\
\hline Bone & $0.7 \pm 0.2$ & $1.3 \pm 0.2$ & $1.2 \pm 0.4$ & $1.1 \pm 0.2$ & $0.5 \pm 0.3$ & $0.5 \pm 0.2$ \\
\hline Intestines* & $0.9 \pm 0.3$ & $1.9 \pm 0.5$ & $3 \pm 2$ & $1.3 \pm 0.4$ & $0.40 \pm 0.07$ & $0.10 \pm 0.02$ \\
\hline Carcass* & $58 \pm 15$ & $46 \pm 2$ & $39 \pm 2$ & $32 \pm 2$ & $12 \pm 1$ & $6.1 \pm 0.4$ \\
\hline
\end{tabular}

${ }^{*}$ Data for intestines with content and carcass are presented as \%ID per whole sample.

Data are presented as average of $\% \mathrm{ID} / \mathrm{g} \pm \mathrm{SD}, n=4$. 
TABLE 3

Dosimetry of ${ }^{177}$ Lu-ABY-027 in Mice in Comparison with ${ }^{177}$ Lu-CHX-A" -DTPA-ABD-(Z ${ }_{\text {HER2:342) }}$ (17)

\begin{tabular}{lcc}
\hline Organ & ${ }^{177}$ Lu-ABY-027 $(\mathrm{Gy} / \mathrm{MBq})$ & ${ }^{177}$ Lu-CHX-A" $-\mathrm{DTPA}-\mathrm{ABD}-\left(\mathrm{Z}_{\mathrm{HER} 2: 342)_{2}(\mathrm{~Gy} / \mathrm{MBq})}\right.$ \\
\hline Blood & $0.42 \pm 0.04$ & $0.51 \pm 0.3$ \\
Heart & $0.21 \pm 0.01$ & $0.25 \pm 0.02$ \\
Lung & $0.27 \pm 0.02$ & $0.33 \pm 0.01$ \\
Liver & $0.28 \pm 0.01$ & $0.76 \pm 0.03$ \\
Spleen & $0.32 \pm 0.04$ & $0.53 \pm 0.4$ \\
Pancreas & $0.091 \pm 0.008$ & $0.12 \pm 0.01$ \\
Stomach & $0.10 \pm 0.01$ & $0.097 \pm 0.003$ \\
Intestine & $0.10 \pm 0.01$ & $0.11 \pm 0.005$ \\
Kidney & $0.35 \pm 0.02$ & $1.49 \pm 0.07$ \\
Tumor & $1.37 \pm 0.22$ & $2.1 \pm 0.2$ \\
Muscle & $0.11 \pm 0.01$ & $0.09 \pm 0.001$ \\
Bone & $0.13 \pm 0.02$ & $0.21 \pm 0.05$ \\
& & \\
\hline
\end{tabular}

As expected, a clear effect on the half-life of ABD binding to the serum albumin was demonstrated. The elimination half-life of the parental $\mathrm{Z}_{\mathrm{HER} 2: 2891}$ Affibody molecule from blood was increased 80 -fold, from $0.5 \mathrm{~h}(24)$ to $41 \mathrm{~h}$. Furthermore, in SKOV-3-xenografted mice biodistribution experiments with ABY-027 labeled with ${ }^{177} \mathrm{Lu}$ showed more than a 3-fold reduced renal accumulation of radioactivity, compared with ${ }^{177} \mathrm{Lu}-\mathrm{CHX}-\mathrm{A}^{\prime \prime}$-DTPA-ABD- $\left(\mathrm{Z}_{\mathrm{HER} 2: 342}\right)_{2}$ (17), with retained tumor uptake. Targeting of HER2expressing xenografts was specific, because saturation of HER2 by preinjection of an excess of nonlabeled ABY-027 caused a significant decrease of tumor uptake (Fig. 4). At the same time, targeting was equally efficient in a broad range of injected protein doses (Fig. 3). Thus, ${ }^{111}$ In-ABY-027 provides an efficient expansion of the plasma half-life and a reduction of renal uptake of Affibody molecules as well as specific and improved targeting of HER2-expressing xenografts in comparison with previously reported ABD$\left(\mathrm{Z}_{\mathrm{HER} 2: 342}\right)_{2}$ (Table 1). Importantly, the circulatory half-life of ${ }^{177} \mathrm{Lu}-\mathrm{ABY}-027$ in mice was 2 - to 2.5 -fold shorter than the half-life of radiolabeled anti-HER2 antibodies $(25,32)$, and the molecular weight of ${ }^{177} \mathrm{Lu}-\mathrm{ABY}-027$-albumin adduct $(\sim 80 \mathrm{kDa})$ is approximately half the weight of an antibody. These together should reduce problems seen when using antibodies for radioimmunotherapy, such as an excessively long residence time in blood and poor tumor penetration. It has been previously shown that the penetration of a Fab-albumin-binding peptide-albumin complex (size, $\sim 120 \mathrm{kDa}$ ) was much better than what would be assumed from its size and at least equal to that of the noncomplexed Fab (19). We have previously shown a curative effect of targeted radionuclide therapy in mice carrying SKOV-3 xenografts using an antiHER2 Affibody molecule fused with the first-generation ABD (17), in contrast to the mAb pertuzumab yielding only prolonged survival in the same tumor model (25).

As discussed above, the current Affibody ABD fusion protein is a development from the first-generation HER2binding $\mathrm{ABD}$ fusion protein $(17,18)$. Recently, Hoppman et al. (33) evaluated the alternative approach of direct chemical coupling of $\mathrm{Z}_{\mathrm{HER} 2: 342}$ to HSA. We have made a comparison of the biodistribution of these different constructs, using the data from $48 \mathrm{~h}$ after injection because this was the only common time point (Table 1 ). The study of the construct ${ }^{111} \mathrm{In}$-DOTA-ABD- $\left(\mathrm{Z}_{\mathrm{HER} 2: 342}\right)_{2}$ was performed in mice xenografted with the low-HER2-expressing cell line LS174T, compared with the other 3 constructs studied, possibly explaining the lower tumor values in xenografts of the high-HER2-expressing cell line SKOV-3. Furthermore, in addition xenografts based on the same cell line may show batch-to-batch variability and variation in biodistribution pattern of the same conjugate labeled with different radionuclides (34). Therefore, comparisons are preferably done head-to-head in the same batch of xenografts, as with ${ }^{111} \mathrm{In}$ ABY-027 and ${ }^{111}$ In-CHX-A" - DTPA-ABD- $\left(Z_{\mathrm{HER} 2: 342}\right)_{2}$ in the present study. However, data from normal tissues should be directly comparable. Despite multiple HER2 bindings, the HSA conjugate did not provide the highest tumor accumulation, compared with the fusion proteins analyzed in the high-HER2-expressing xenograft model. Furthermore, the high levels in the liver and spleen, as well as the faster clearance, suggest negative effects of multiple random conjugations on the properties of albumin. On the contrary, the novel fusion protein based on affinity-matured ABD provided the lowest kidney values and also the lowest values in the liver and spleen. A comparison of dosimetry of ${ }^{177} \mathrm{Lu}-$ ABY-027 and ${ }^{177}$ Lu-CHX-A" - DTPA-ABD- $\left(Z_{\text {HER } 2: 342}\right)_{2}$ (17) are presented in Table 3 . Both calculations were based on the same methodology, and the biodistribution input data were obtained in the same animal model, BALB/C $n u / n u$ mice bearing SKOV-3 xenografts. A curative effect was obtained after injection of $21.6 \mathrm{MBq}$ of ${ }^{177} \mathrm{Lu}-\mathrm{CHX}-$ $\mathrm{A}^{\prime \prime}$-DTPA-ABD-(Z $\mathrm{HER} 2: 342_{2}$ (17). With ${ }^{177} \mathrm{Lu}-\mathrm{ABY}-027$, the same dose to tumor would be achieved with 33.1 $\mathrm{MBq}$. With the specific activity used in the present study, this administration of such activity would require injection of $22-25 \mu \mathrm{g}$ of ${ }^{177} \mathrm{Lu}-\mathrm{ABY}-027$ per mouse. As shown in the 
present study, injection of such a protein dose is in a range where small differences in the injected protein dose insignificantly affect tumor uptake. A comparison at equal dose to tumor shows that the dose to blood and bone would be similar for the 2 constructs and that ${ }^{177} \mathrm{Lu}-\mathrm{ABY}-027$ would give a 2.8 and 1.8-fold-lower dose to kidney and liver, respectively.

\section{CONCLUSION}

$\mathrm{Z}_{\mathrm{HER} 2 \mathrm{2891}}-\mathrm{ABD}_{035}$-DOTA (ABY-027) is a fusion protein having a biodistribution suitable for therapy and showing retained HER2-specific binding. The capacity of specific targeting of HER2-expressing xenografts was shown in vivo. In a murine model, ${ }^{177} \mathrm{Lu}-\mathrm{ABY}-027$ provided an appreciable reduction of renal and hepatic uptake of radioactivity in comparison with alternative approaches. Site-specific conjugation of DOTA provides a uniform conjugate and creates the potential for labeling with a broad range of therapeutic radionuclides. The unique cysteine can also be used for site specific coupling of other effector functions.

\section{DISCLOSURE}

The costs of publication of this article were defrayed in part by the payment of page charges. Therefore, and solely to indicate this fact, this article is hereby marked "advertisement" in accordance with 18 USC section 1734. This work was supported by grants from Swedish Research Council (Vetenskapsrådet) and Swedish Cancer Society (Cancerfonden). Affibody AB holds intellectual property rights and trademarks for Affibody molecules, which might be considered as a potential conflict of interest. However, we believe that we have presented data and considerations in a scientifically strict and unbiased way and refer to results published in established international peer-review journals. No other potential conflict of interest relevant to this article was reported.

\section{REFERENCES}

1. Carlsson J. Potential for clinical radionuclide-based imaging and therapy of common cancers expressing EGFR-family receptors. Tumour Biol. 2012;33: 653-659.

2. Buzdar AU, Ibrahim NK, Francis D, et al. Significantly higher pathologic complete remission rate after neoadjuvant therapy with trastuzumab, paclitaxel, and epirubicin chemotherapy: results of a randomized trial in human epidermal growth factor receptor 2-positive operable breast cancer. J Clin Oncol. 2005;23: 3676-3685.

3. Nahta R, Esteva FJ. Trastuzumab: triumphs and tribulations. Oncogene. 2007;26: 3637-3643.

4. Senter PD. Potent antibody drug conjugates for cancer therapy. Curr Opin Chem Biol. 2009;13:235-244.

5. Kassis AI, Adelstein SJ. Radiobiologic principles in radionuclide therapy. $\mathrm{J} \mathrm{Nucl}$ Med. 2005;46(suppl 1):4S-12S.

6. Goldsmith SJ. Radioimmunotherapy of lymphoma: Bexxar and Zevalin. Semin Nucl Med. 2010;40:122-135.

7. Sharkey RM, Goldenberg DM. Perspectives on cancer therapy with radiolabeled monoclonal antibodies. J Nucl Med. 2005;46(suppl 1):115S-127S.

8. Jain M, Venkatraman G, Batra SK. Optimization of radioimmunotherapy of solid tumors: biological impediments and their modulation. Clin Cancer Res. 2007;13: 1374-1382.

9. Behr TM, Goldenberg DM, Becker W. Reducing the renal uptake of radiolabeled antibody fragments and peptides for diagnosis and therapy: present status, future prospects and limitations. Eur J Nucl Med. 1998;25:201-212.
10. Schmidt MM, Wittrup KD. A modeling analysis of the effects of molecular size and binding affinity on tumor targeting. Mol Cancer Ther. 2009;8:28612871.

11. Orlova A, Magnusson M, Eriksson TL, et al. Tumor imaging using a picomolar affinity HER2 binding affibody molecule. Cancer Res. 2006;66:43394348.

12. Nygren P-Å. Alternative binding proteins: Affibody binding proteins developed from a small three-helix bundle scaffold. FEBS J. 2008;275:26682676 .

13. Löfblom J, Feldwisch J, Tolmachev V, Carlsson J, Ståhl S, Frejd FY. Affibody molecules: engineered proteins for therapeutic, diagnostic and biotechnological applications. FEBS Lett. 2010;584:2670-2680.

14. Baum RP, Prasad V, Müller D, et al. Molecular imaging of HER2-expressing malignant tumors in breast cancer patients using synthetic ${ }^{111} \mathrm{In}$ - or ${ }^{68} \mathrm{Ga}$-labeled affibody molecules. J Nucl Med. 2010;51:892-897.

15. Orlova A, Tolmachev V, Pehrson R, et al. Synthetic affibody molecules: a novel class of affinity ligands for molecular imaging of HER2-expressing malignant tumors. Cancer Res. 2007;67:2178-2186.

16. Fortin MA, Orlova A, Malmström PU, Tolmachev V. Labelling chemistry and characterization of $\left[{ }^{90} \mathrm{Y} /{ }^{177} \mathrm{Lu}\right]-D O T A-Z_{\mathrm{HER} 2: 342^{-}}$Affibody molecule, a candidate agent for locoregional treatment of urinary bladder carcinoma. Int $\mathrm{J} \mathrm{Mol}$ Med. 2007;19:285-291.

17. Tolmachev V, Orlova A, Pehrson R, et al. Radionuclide therapy of HER2-positive micro-xenografts using a ${ }^{177} \mathrm{Lu}$-labeled HER2-specific Affibody molecule. Cancer Res. 2007;67:2773-2782.

18. Tolmachev V, Wållberg H, Andersson K, Wennborg A, Lundqvist H, Orlova A. The influence of Bz-DOTA and CHX-A"-DTPA on the biodistribution of ABDfused anti-HER2 Affibody molecules: implications for (114m)In-mediated targeting therapy. Eur J Nucl Med Mol Imaging. 2009;36:1460-1468.

19. Dennis MS, Jin H, Dugger D, et al. Imaging tumors with an albumin-binding Fab, a novel tumor-targeting agent. Cancer Res. 2007;67:254-261.

20. Kratz F. Albumin as a drug carrier: Design of prodrugs, drug conjugates and nanoparticles. J Control Release. 2008;132:171-183.

21. Jonsson A, Dogan J, Herne N, Abrahmsén L, Nygren PA. Engineering of a femtomolar affinity binding protein to human serum albumin. Protein Eng Des Sel. 2008;21:515-527.

22. Feldwisch J, Tolmachev V, Lendel C, et al. Design of an optimized scaffold for affibody molecules. J Mol Biol. 2010;398:232-247.

23. Sandberg D, Wennborg A, Feldwisch J, et al. First clinical observations of HER2 specific [ $\left.{ }^{111} \mathrm{In}\right] \mathrm{ABY}-025$ metastatic detection capability in females with metastatic breast cancer [abstract]. J Nucl Med. 2012;53(suppl 1):220.

24. Ahlgren S, Orlova A, Wållberg H, et al. Targeting of HER2-expressing tumors using ${ }^{111}$ In-ABY-025, a second-generation affibody molecule with a fundamentally reengineered scaffold. J Nucl Med. 2010;51:1131-1138.

25. Tolmachev V, Tran TA, Rosik D, Sjöberg A, Abrahmsén L, Orlova A. Tumor targeting using affibody molecules: interplay of affinity, target expression level, and binding site composition. J Nucl Med. 2012;53:953-960.

26. Wållberg H, Orlova A. Slow internalization of anti-HER2 synthetic affibody monomer ${ }^{111}$ In-DOTA-Z $Z_{\text {HER2:342-pep2: implications for development of labeled }}$ tracers. Cancer Biother Radiopharm. 2008;23:435-442.

27. Smith-Jones PM, Solit DB, Akhurst T, Afroze F, Rosen N, Larson SM. Imaging the pharmacodynamics of HER2 degradation in response to Hsp90 inhibitors. Nat Biotechnol. 2004;22:701-706.

28. Adams GP, Shaller CC, Dadachova E, et al. A single treatment of yttrium-90labeled CHX-A"-C6.5 diabody inhibits the growth of established human tumor xenografts in immunodeficient mice. Cancer Res. 2004;64:6200-6206.

29. Zahnd C, Kawe M, Stumpp MT, et al. Efficient tumor targeting with high-affinity designed ankyrin repeat proteins: effects of affinity and molecular size. Cancer Res. 2010;70:1595-1605.

30. Vaneycken I, Devoogdt N, Van Gassen N, et al. Preclinical screening of antiHER2 nanobodies for molecular imaging of breast cancer. FASEB J. 2011;25: 2433-2446.

31. Andersen JT, Pehrson R, Tolmachev V, Daba MB, Abrahmsén L, Ekblad C. Extending half-life by indirect targeting of the neonatal $\mathrm{Fc}$ receptor (FcRn) using a minimal albumin binding domain. J Biol Chem. 2011;286:5234-5241.

32. Garmestani K, Milenic DE, Plascjak PS, Brechbiel MW. A new and convenient method for purification of ${ }^{86} \mathrm{Y}$ using a $\mathrm{Sr}$ (II) selective resin and comparison of biodistribution of ${ }^{86} \mathrm{Y}$ and ${ }^{111}$ In labeled Herceptin. Nucl Med Biol. 2002;29: 599-606.

33. Hoppmann S, Miao Z, Liu S, et al. Radiolabeled affibody-albumin bioconjugates for HER2-positive cancer targeting. Bioconjug Chem. 2011;22:413-421.

34. Lövqvist A, Humm JL, Sheikh A, et al. PET imaging of ${ }^{86}$ Y-labeled anti-Lewis Y monoclonal antibodies in a nude mouse model: comparison between ${ }^{86} \mathrm{Y}$ and ${ }^{111}$ In radiolabels. $J$ Nucl Med. 2001;42:1281-1287. 